\title{
Determinants of patient satisfaction towards inpatient nursing services and its associated factors in, Gamo Gofa Zone, SNNPR, Ethiopia,April 2017
}

\begin{abstract}
Background: Patient satisfaction is the perception of care received compared with the care expected and patients thereby evaluate the health-care services as well as the providers from their own subjective point of view. Patient satisfaction with nursing care is considered an important factor in explaining patients' perceptions of service quality.

Objective: To assess the level of Patient satisfaction towards inpatient nursing services and its determinants in Arba Minch general hospital Gamo Gofa zone, SNNPR, Ethiopia, April 2017.

Methods: A Cross-Sectional Survey was conducted among adult patients admitted to medical, surgical and gynecological wards of Arba Minch General Hospitals on April 2017. Data was collected in accordance with a modified 'Newcastle Satisfaction with Nursing Scale' (NSNS). Data was analyzed by using statistical package for social sciences/SPSS version 20.

Results: There were 323 study participants involved in this study. Majority of them $208(64.4 \%)$ were females followed by $115(35.6 \%)$ males. More than one third $127(39.3 \%)$ of study participants were in Age range of 25-34years with Mean age of $33.65 \pm(\mathrm{SD}=10.48)$ years . Majority of participants $198(61.3 \%)$ were admitted for $1-5$ days followed by $58(18.0 \%)$ were admitted for $11-15$ days and mean duration of hospitalization of study participants was $6.68 \pm(\mathrm{SD}=5.65)$ days. Overall patient satisfaction about inpatient nursing service in the hospital was 132(40.9\%). Age category 35-44years, Respondents attended college and University, Rural residents, Patients admitted to Medical ward, Patients admitted several times and patients admitted second time, Patients with history of surgical operation and Duration of hospitalization more than 15 days were factors associated patient satisfaction.

Conclusion: Based on this study we conclude that the level of overall adult Patient satisfaction about inpatient nursing service in the hospital was very low. The amount and type of information provided for patients was poor, nurses' awareness about patient needs and keeping privacy of patients in all wards was also low. This requires imperative attention by responsible bodies to enhance patient satisfaction.
\end{abstract}

Keywords: patient satisfaction, nursing care, inpatient, Arba minch, Ethiopia

\author{
Volume 7 Issue $3-2017$
}

\author{
Mende Mensa, Azeb Taye, Samson Katene, \\ Fikrte Abera, Olamo Ochare \\ Arba Minch University, Ethiopia
}

Correspondence: Mende Mensa, B.Pharm, MSC. clinical pharmacy, researcher and senior lecturer, Arba Minch College of Health Sciences, Arba Minch University, Ethiopia, Fax +25104688I I I47, Tel +2510937170976, Email mendemensa@gmail.com

Received: September 08, 2017 | Published: September 28, 2017

\section{Introduction}

\section{Background}

Patient satisfaction is the perception of care received compared with the care expected and patients thereby evaluate the health-care services as well as the providers from their own subjective point of view. Patients provide the best source of accurate information regarding clarity of explanations, helpfulness of information patients are receiving, barriers to obtaining care or the professional's interpersonal behavior.

It is important to make the organization and delivery of health care responsive to consumer opinion, because consumer satisfaction is being adopted as a standard component of evaluative research and assessments of quality as to the design and management of health care systems. ${ }^{2,3}$ Patient satisfaction with nursing care is considered an important factor in explaining patients' perceptions of service quality. ${ }^{4,5}$
Growing demand for health care, rising costs, constrained resources, and evidence of variations in clinical practice have increased interest in measuring and improving the quality of health care in many countries of the world.

Nursing services are the backbone of the health care system in almost all countries in the world since they represent between $60-70 \%$ of the health care personnel. ${ }^{7}$ Therefore, the level of patients' satisfaction is one among the mechanisms used in assessing the quality of health care services and addressing patients' expectations was found to be associated with high client satisfaction and better health outcomes. ${ }^{8}$ Evidence demonstrates increasing nursing staff could reduce costs and improve patient care by reducing unnecessary deaths and reducing days in the hospital. A 10\% increase in the number of patients assigned to a nurse leads to a $28 \%$ increase in adverse events such as infections, medication errors, and other injuries. Understaffing of registered nurses in hospital intensive care units increases the risk of serious infections for patients. ${ }^{9}$ 


\section{Patient satisfaction as a measure of quality of care}

Patients have explicit desire or needs for care when they visit hospitals. However, inadequate response to their needs or expectations could result in patient dissatisfaction. There is growing consensus that assessment of the quality of hospital services should be based in part, on patients' perceptions of overall care and satisfaction. Patient satisfaction influences their compliance with treatment, seeking of medical advice and maintains a continuing relationship with practitioners. Measurement of patient satisfaction has become an integral part of hospital management strategies worldwide. Provision of health care is expected to respond directly to patients' preferences and demands and the efficacy of medical treatment is enhanced by greater patient satisfaction. ${ }^{10}$ According to $\mathrm{WHO}$, the health and well- being of people depend on the performance of the health system and assessment of patients' satisfaction level, as part of health system responsiveness, is one of the five indicators for measuring performance of health system. ${ }^{11}$

In Ethiopia, health sector development plan three/HSDP III (20052010) of the FMOH had focused to strengthening the management capacity of health facilities in addition to the construction and expansion of health facilities, one of the strategic objectives of the currently operational HSDP IV (2010-2015) is to improve quality of health services in order to satisfy the community's health care needs through the delivery of relevant, safe and optimum quality health services. ${ }^{12}$

\section{Nursing care and patient satisfaction}

Nursing care has impact on the provision of care that is safe, effective, patient-centered, timely, efficient, and equitable services. The adequacy of nursing staffing and proportion of registered nurses is inversely related to the death rate of acute medical patients within 30days of hospital admission. Increasing $\mathrm{RN}$ staffing could reduce costs and improve patient care by reducing unnecessary deaths and reducing days in the hospital. ${ }^{13}$ A $10 \%$ increase in the number of patients assigned to a nurse leads to a $28 \%$ increase in adverse events such as infections, medication errors, and other injuries. Understaffing of registered nurses in hospital intensive care units increases the risk of serious infections for patients; specifically pneumonia. ${ }^{14,15}$

Cross sectional study conducted in Turkey to assess patient satisfaction showed that the type of ward, sex, income, and education were factors independently affected the satisfaction with Nursing Care. Patient who underwent surgical procedures, male patients, the 40-59year old age group those who had low levels of education or income, and patients who were hospitalized for longer periods were most satisfied. Patients age, sex, income, ward type were important factors that affected their satisfaction with nursing care. ${ }^{6}$ Literature review conducted of Cumulative Index of Nursing and Allied Health Literature and MEDLINE databases and the ABI/INFORM global business database on patient satisfaction with nursing care using a nursing model by using 44 papers published in English, between 1998 and 2007 showed that Antecedents embodied the uniqueness of the patient in terms of demographic data, social influence, previous healthcare experiences, environmental resources, intrinsic motivation, cognitive appraisal and affective response. ${ }^{16-20}$

A study in Pakistan on patient level of satisfaction with various aspects of care provided by doctors in surgical ward indicated that care givers' politeness, consultation and respect for privacy being key determinants of users' perception of satisfaction. Aspects of care such as seeking patients' participation in discussion of their illness, explaining them prescription drugs and lab investigations are areas required attention, especially with regard socio demographic factors like age and education. ${ }^{21}$

Studies around the world have also noted that patient satisfaction is associated with increased compliance with the prescribed treatment and discharge instructions, reduction of complaints against the institution and improvement of morale and job satisfaction among health-care providers, which in turn can be of benefit to both patients' health outcomes and relationships with health-care professionals. ${ }^{22}$

Studies indicated that patient satisfaction condition associated with patient characteristics, such as age, sex, educational level, work status and health status. A study indicated that varying importance of some socio-demographic variables, length of stay and previous admission. Older respondents generally record higher satisfaction and satisfaction linked to prior satisfaction with health care and granting patient desires. ${ }^{23}$

A study in Hong Kong indicated that communication, respect and patient engagement I provider-patient relationship and patient sociodemographic characteristics including age gender, race, educational level, health status and previous admissions and the length of the current admission affect patient satisfaction level. ${ }^{24}$

A study done in Bangladesh indicated that the most powerful predictor for client satisfaction with the government services was provider behavior, especially respect and politeness. The second most powerful predictor for being satisfied was the respect for privacy, followed by short waiting times. ${ }^{25}$

Treatment outcomes are more favorable when patients feel they are active participants in care and that their problem has been discussed fully, when they feel encouraged to ask questions, when they feel emotionally supported and when they share their ideas or feelings in the treatment planning process. ${ }^{26}$

The study in Jimma specialized hospital indicated, satisfaction with the health care was found to have a significant association with the age of the respondents $(p=0.034)$ and educational level of the respondents $(\mathrm{p}=0.003){ }^{12}$

Study conducted on Adult Patients' Satisfaction with Inpatient Nursing Care in northeast Ethiopia showed that Female patients were more likely to be satisfied with the nursing care as compared to male patients. Patients within the age group of 18-30years were more likely to be satisfied with the nursing care as compared to patients above the age of 61. Patients who were admitted in ophthalmology ward were more likely to be satisfied as compared to patients admitted in medical ward. In addition, patients who perceive their current health is in good condition were more likely to be satisfied as compared to those who perceive their current health status is in poor condition. ${ }^{27}$

A study in Tikur Anbassa indicated overall participants' satisfaction $90 \%$ with nursing care. Female and age (18-30yrs) had higher satisfaction than males and older participants'. Number of nights spent in the ward had also an association with satisfaction. Those who stayed 11-21 nights had lesser satisfaction than those who stayed less than 10days. It was indicated that, the cause of dissatisfaction is not due to nursing care but other hospital services such as pharmacy, laboratory, catering and other services. ${ }^{27}$ 
Nurses are frontline health care providers having 24hour contact with patients as well as being near to them. They should fulfil what patients expect more from them with competence and a compassionate approach. Nursing services are not organized well in Ethiopia and the government developed companionate respectful and caring/ CRC to improve quality of health care. Besides the limited studies undertaken on Patient satisfaction and associated factors in Ethiopia, there is no research based evidence in our study area of interest so far. The study might significantly help in planning and implementing the future strategies for improving health care delivery and provide pathways and information for other researchers who want to conduct further study on similar issue.

\section{Materials and methods}

\section{Study area and period}

This study was conducted from April 30-May 20/2017 at Arba Minch general hospital. Arba Minch General Hospital was established in 1961 E.C and located in Arba Minch town, the capital city of Gamo Gofa zone, southern Ethiopia. Gamo Gofa zone is one of the zones that are found in Southern, Nations, Nationality and People Regional state (SNNPR), which is $505 \mathrm{~km}$ form Addis Ababa (capital city of Ethiopia) and about $280 \mathrm{Km}$ from Hawassa (center of SNNPR). Arba Minch has two sub cities, namely Secha and Sikela. The hospital is located in Secha which is the administrative center of Arba Minch town. The hospital provides preventive, curative and rehabilitative care for people from Gamo Gofa Zone and other nearby zones. The hospital has a total of 410 workers. Among these 251 are health professionals, and 159 are administrative staffs.

\section{Study design}

Institutional based Cross-Sectional study design was utilized.

\section{Source population}

11 adult patients who were admitted to the Medical, Surgical, and Gynecology wards of Arba Minch General Hospital.

\section{Study population}

Patients who are admitted to the study wards in the study hospitals at the time of data collection and met the inclusion criteria.

\section{Inclusion and exclusion criteria}

\section{Inclusion criteria}

Patient who are $>18$ years of age.

\section{Exclusion criteria}

Patients who are seriously ill and unable to communicate were excluded.

\section{Sample size and sampling procedure}

\section{Sample size}

Sample size was determined by single population proportion formula and the following assumptions were made: level of confidence $95 \%$; $\mathrm{Z} \alpha / 2=1.96$, a $5 \%$ margin of error $(\mathrm{d}=0.05)$, and a proportion of patient satisfaction of $67 \%$ (33). The sample size was 340 and, adding for $5 \%$ possible non response rate, the total sample size was 357 patients. $\mathrm{n}=(\mathrm{Z} \alpha / 2)^{2} \mathrm{P}(1-\mathrm{P}) \mathrm{d}^{2}$

Where: $\mathrm{P}=$ proportion of patient satisfaction
$\mathrm{Z} \alpha / 2$ at $95 \% \mathrm{CI}=1.96$

Margin of error $(D)=0.05$

\section{Sampling procedure}

Patients fulfilling the inclusion criteria and admitted to medical, surgical and obstetrics and gynecology wards of Arba Minch General Hospital during data collection period and stayed for at least one night before data collection in the respective ward were included.

\section{Study Variable}

\section{Dependent variable}

Patient Satisfaction

\section{Independent variables}

Age; gender; income; educational status; admission Ward; history of admission and nursing care provided.

\section{Data collection instrument and procedure}

Data was collected by using modified Newcastle Satisfaction with Nursing Scale (NSNS). The questionnaire was translated to Amharic for interview. The satisfaction scale consists of 19-items. All items are scored on a five-point Likert scale (1=very dissatisfied, $2=$ dissatisfied, $3=$ Neutral, 4=Satisfied, and 5=Very Satisfied). Participants were asked to rate their satisfaction with various aspects of nursing care by selecting only one number that best described their opinion on each item of the scale. The tool was pretested on $5 \%$ of patients who were not included in the actual study; necessary correction was made based on findings from pretest. The four final year nursing students for data collection and two senior nurses one from medical and one from surgical ward were recruited as supervisor. Brief one day orientation about principles and procedures of data collection was given by research team for data collectors and supervisors.

\section{Data processing and analysis}

Data was entered into EPI-data 3.1 and exported to SPSS 20.0 for analysis. Descriptive statistics was computed and binary logistic regression was also conducted to examine the effect of study variables on patients' satisfaction with nursing care. Patient Satisfaction score was computed and Patients were labeled as "Satisfied" if they answered Satisfied and Very satisfied for the tool designed to assess patient satisfaction and "Not satisfied" if they responded Neutral, Dissatisfied and very dissatisfied for the designed tool. Percentage of overall satisfaction was calculated by the following formula:-

$$
\begin{gathered}
\% \text { Satisfied in each ward }=\frac{\text { Number participants responded satisfied and very satisfied in each ward }}{\text { Total population in each ward }} \times 100 \\
\% \text { not Satisfied in each ward }=\frac{\text { Number participants responded neutral,dissatified and very dissatisfied }}{\text { Total population in each ward }} \times 100 \\
\text { Overall\%Satisfaction }=\frac{\text { Sum of participants satisfied in each ward }}{\text { Total population }} \times 100
\end{gathered}
$$

\section{Data quality assurance}

Data collectors and coordinators will trained and the data collection procedure is checked regularly, through supervision and frequent checking of information collected for its consistency on the same day by the coordinators and principal investigators. Collected data was checked by principal investigators for completeness before entering into EPI-data 3.1. Then the data was coded and data template was prepared with double checking for validity. 


\section{Results}

\section{Socio demographic data}

There were 323 study participants involved in this study with response rate of $90.5 \%$. Majority of them 208(64.4\%) were females followed by $115(35.6 \%)$ males. More than one third $127(39.3 \%)$ of study participants were in Age range of 25-34years with Mean age of $33.65 \pm(\mathrm{SD}=10.48)$ years, ranging from 18 -60years . With regard to marital status majority $215(66.6 \%)$ were married followed by $69(21.4 \%)$ single. More than one half $192(59.4 \%)$ of study participants had family size of 1-5 members and mean family size was $5.72 \pm(\mathrm{SD}=3.11)$, ranging from $2-16$ family members. more than one third $124(38.4 \%)$ of study participants completed secondary school followed by $84(26.0 \%)$ illiterate. About one forth $82(25.4 \%)$ study participants were housewives with regard to occupational status followed by $68(21.1 \%)$ farmers (Table 1$)$.

Others: students

\section{Patient Hospitalization related factors}

More than one half $185(57.3 \%)$ study participants were admitted to medical ward, $80(24.8 \%)$ to obstetric and gynaecological ward and $58(18.0 \%)$ to surgical ward. More than one third $142(44.0 \%)$ of participants were admitted for the first time followed by $127(39.3 \%)$ for the second time. Regarding duration of hospitalization majority of participants $198(61.3 \%$ ) were admitted for 1-5days followed by $58(18.0 \%)$ were admitted for 11-15days and mean duration of hospitalization of study participants was $6.68 \pm(\mathrm{SD}=5.65)$ days, ranging from 1-28days (Table 2).

Table I Distribution of socio demographic and hospitalization related factors of study participants who had been admitted to Arba Minch general hospital, southern Ethiopia, May 2017

\begin{tabular}{|c|c|c|c|}
\hline Sociodemographic characteristics & & Frequency & Percent \\
\hline \multirow[t]{2}{*}{ Sex } & Male & 115 & 35.6 \\
\hline & Female & 208 & 64.4 \\
\hline \multirow[t]{4}{*}{ Age category } & $15-24$ years & 65 & 20.1 \\
\hline & $25-34$ years & 127 & 39.3 \\
\hline & $35-44$ years & 66 & 20.4 \\
\hline & 45 and above years & 65 & 20.1 \\
\hline \multirow[t]{5}{*}{ Marital status } & Married & 215 & 66.6 \\
\hline & Single & 69 & 21.4 \\
\hline & Separated & 27 & 8.4 \\
\hline & Divorced & 7 & 2.2 \\
\hline & Widowed & 5 & 1.5 \\
\hline \multirow[t]{3}{*}{ Family size } & I-5 members & 192 & 59.4 \\
\hline & 6-10 members & 105 & 32.5 \\
\hline & Above 10 members & 26 & 8 \\
\hline \multirow[t]{4}{*}{ Educational status } & Illiterate & 84 & 26 \\
\hline & Primary school & 54 & 16.7 \\
\hline & Secondary School & 124 & 38.4 \\
\hline & College and University & 61 & 18.9 \\
\hline \multirow[t]{7}{*}{ Occupational status } & Farmer & 68 & 21.1 \\
\hline & Housewife & 82 & 25.4 \\
\hline & Government employee & 65 & 20.1 \\
\hline & Private employee & 40 & 12.4 \\
\hline & Merchant & 40 & 12.4 \\
\hline & Retired & 25 & 7.7 \\
\hline & Others & 3 & 0.9 \\
\hline \multirow[t]{2}{*}{ Residence } & Urban & 167 & 51.7 \\
\hline & Rural & 156 & 48.3 \\
\hline \multicolumn{4}{|l|}{ Hospitalization Related Factors } \\
\hline \multirow[t]{2}{*}{ Type of ward } & Medical & 185 & 57.3 \\
\hline & Surgical & 58 & 18 \\
\hline
\end{tabular}


Table Continued.

\begin{tabular}{|c|c|c|c|}
\hline Sociodemographic characteristics & & Frequency & Percent \\
\hline & Obstetric and gynaecological & 80 & 24.8 \\
\hline \multirow[t]{3}{*}{ History of hospitalization } & First time & 142 & 44 \\
\hline & Second time & 127 & 39.3 \\
\hline & Several times & 54 & 16.7 \\
\hline \multirow[t]{2}{*}{ History of surgical operation } & Yes & 121 & 37.5 \\
\hline & No & 202 & 62.5 \\
\hline \multirow[t]{4}{*}{ Duration of hospitalization } & I-5 days & 198 & 61.3 \\
\hline & 6-10 days & 50 & 15.5 \\
\hline & II-I5 days & 58 & 18 \\
\hline & Above 15 days & 17 & 5.3 \\
\hline \multirow[t]{3}{*}{ Availability of specific nurse assigned for patient care } & Yes & 219 & 67.8 \\
\hline & No & 60 & 18.6 \\
\hline & Not sure & 44 & 13.6 \\
\hline
\end{tabular}

Table 2 Distribution patient satisfaction score among study participants who had been admitted to Arba Minch general hospital, southern Ethiopia, May 2017

\begin{tabular}{|c|c|c|c|c|c|}
\hline S.No & Patient satisfaction assessment tool score & Dissatisfied & Neutral & Satisfied & $\begin{array}{l}\text { Very } \\
\text { Satisfied }\end{array}$ \\
\hline I & The amount of time nurses spent with you & 57 & 26 & 206 & 39 \\
\hline 2 & How capable nurses were at their job & 43 & 30 & 219 & 31 \\
\hline 3 & There always being a nurse around if you needed one & 69 & 20 & 201 & 33 \\
\hline 4 & The amount nurses knew about your care & 59 & 26 & 216 & 22 \\
\hline 5 & How quickly nurses came when you called for Them & 51 & 36 & 221 & 15 \\
\hline 6 & The way the nurses made you feel at home & 78 & 46 & 183 & 16 \\
\hline 7 & $\begin{array}{l}\text { The amount of information nurses gave to you about your condition and } \\
\text { treatment }\end{array}$ & 133 & 53 & 135 & 2 \\
\hline 8 & How often nurses checked to see if you were Okay & 84 & 41 & 192 & 6 \\
\hline 9 & Nurses' helpfulness & 54 & 47 & 201 & 21 \\
\hline 10 & The way nurses explained things to you & 78 & 23 & 207 & 15 \\
\hline II & How nurses helped put your relatives' or friends' minds at rest & 116 & 30 & 158 & 19 \\
\hline 12 & Nurses' manner in going about their work & 77 & 21 & 213 & 12 \\
\hline 13 & $\begin{array}{l}\text { The type of information nurses gave to you about your condition and } \\
\text { treatment }\end{array}$ & 129 & 42 & 140 & 12 \\
\hline 14 & Nurses' treatment of you as an individual & 69 & 32 & 157 & 65 \\
\hline 15 & How nurses listened to your worries and Concerns & 83 & 33 & 198 & 9 \\
\hline 16 & The amount of freedom you were given on the Ward & 68 & 14 & 224 & 17 \\
\hline 17 & How willing nurses were to respond to your Requests & 82 & 22 & 208 & 11 \\
\hline 18 & The amount of privacy nurses gave you & 122 & 39 & 155 & 7 \\
\hline 19 & Nurses' awareness of your needs & 147 & 44 & 130 & 2 \\
\hline
\end{tabular}




\section{Patient satisfaction about inpatient nursing service}

Participants were asked a series of 19 questions to determine their perception about inpatient nursing service provided for them in respective wards. Majority of respondents 116(62.7\%), 51(87.9\%) and $73(91.3 \%)$ of respondents were satisfied with the amount of time nurses spent with them in medical, surgical and Obstetrics and gynecology wards respectively. Regarding capability of nurses at their job $128(69.2 \%), 49(84.5 \%)$ and $73(91.3 \%)$ of respondents were satisfied with the amount of time nurses spent with them in medical, surgical and Obstetrics and gynecology wards respectively. one hundred seven $47.8 \%, 53(89.7 \%)$ and $77(96.2 \%)$ of respondents were satisfied with the presence of nurses around if they needed them in medical, surgical and Obstetrics and gynecology wards respectively. Majority 100(54.1\%) and 42972.4\%) and 44(55.0\%) were not satisfied with the amount of information nurses gave to them about their condition and treatment in medical, surgical and Obstetrics and gynecology wards respectively. One hundred nineteen $64.3 \%$, $22(37.9 \%)$, and $31(38.8 \%)$ of respondents were not satisfied with the type of information nurses gave to them about their condition and treatment in medical, surgical and Obstetrics and gynecology wards respectively. with regard to Nurses' awareness of patient needs $120(64.8 \%), 34(38.6 \%)$ and $37(46.3 \%)$ were not satisfied in medical, surgical and Obstetrics and gynecology wards respectively. Concerning Patient privacy given by nurses $87(47.0 \%)$, 44(75.9\%) and $64(80.0 \%)$ were not satisfied in medical, surgical and Obstetrics and gynecology wards respectively. The overall Patient satisfaction in respective wards was $65(35.1 \%), 24(41.4 \%)$ and $43(53.7 \%)$ in medical, surgical and Obstetrics and gynecology wards respectively. Overall patient satisfaction about inpatient nursing service in the hospital was 132(40.9\%) and 191(59.1\%) were not satisfied with nursing care provided to them (Table 3 ).

\section{Perception of Patients about overall nursing service in the Hospital}

More than one third $122(37.7 \%)$ reported that nursing care service is Very good, 62(19.20\%) good, 66(20.43\%), 22(6.81\%) Excellent, $37(11.46 \%)$ poor, $9(2.79 \%)$ Very poor and $5(1.55 \%)$ reported nursing care service in the hospital was Dreadful (Figure 1).
Participants were asked to describe openly about problems in nursing care service and hospital performance and more than one quarter $89(27.6 \%)$ of participants reported that there was shortage of bed sheets; $62(19.2 \%)$ reported shortage of drugs; $57(17.6 \%)$ reported inadequate water supply and $48(14.9 \%)$ reported that nurses have punctuality Problem. finally 52(16.1\%) reported they have no idea and $15(4.6 \%)$ reported that nurses lack motivation (Figure 2).

\section{Factors associated with patient satisfaction in inpatient nursing care}

Binary logistic regression showed that Age category 35-44years, educational Status College and University, Rural residence, Admission to medical ward, repeated hospitalization, history of surgical operation and duration of hospitalization were factors associated with Patient satisfaction in inpatient nursing care service.

Variables statistically significant in binary logistic regression were entered into Multivariable logistic regression to identify factors predicting adult patient satisfaction in inpatient nursing care service. Age category 35-44years were 2.7times $[\mathrm{AOR}=2.795(1.224,6.381]$ more likely to be satisfied with nursing care service provided when compared with 15-24years. Respondents attended college and University were 1.6 times $[\mathrm{AOR}=1.618(1.572,3.392]$ more likely to be satisfied with nursing care service provided than illiterate once. Rural residents were 1.1 times $[\mathrm{AOR}=1.135$ (1.123, 2.035] more likely to be satisfied with inpatient nursing care service than urban residents. Patients admitted to Medical ward were $[\mathrm{AOR}=0.349$ $(0.162,0.751]$ less likely to be satisfied with inpatient nursing care service than those admitted to obstetrics and gynaecology ward. Patients admitted several times and patients admitted second time were $[\mathrm{AOR}=0.364(0.154,0.858]$ and $[\mathrm{AOR}=0.262(0.105,0.657]$ less likely to be satisfied with inpatient nursing care provided when compared with those admitted for the first time. Patients with history of surgical operation were $[\mathrm{AOR}=0.925(0.519,0.948]$ less likely to be satisfied than those with no history of surgical operation. Patients who were admitted for more than 15 days were $[\mathrm{AOR}=0.236(0.061$, $0.911]$ less likely to be satisfied with inpatient nursing care service than those admitted for 1-5days (Table 4).

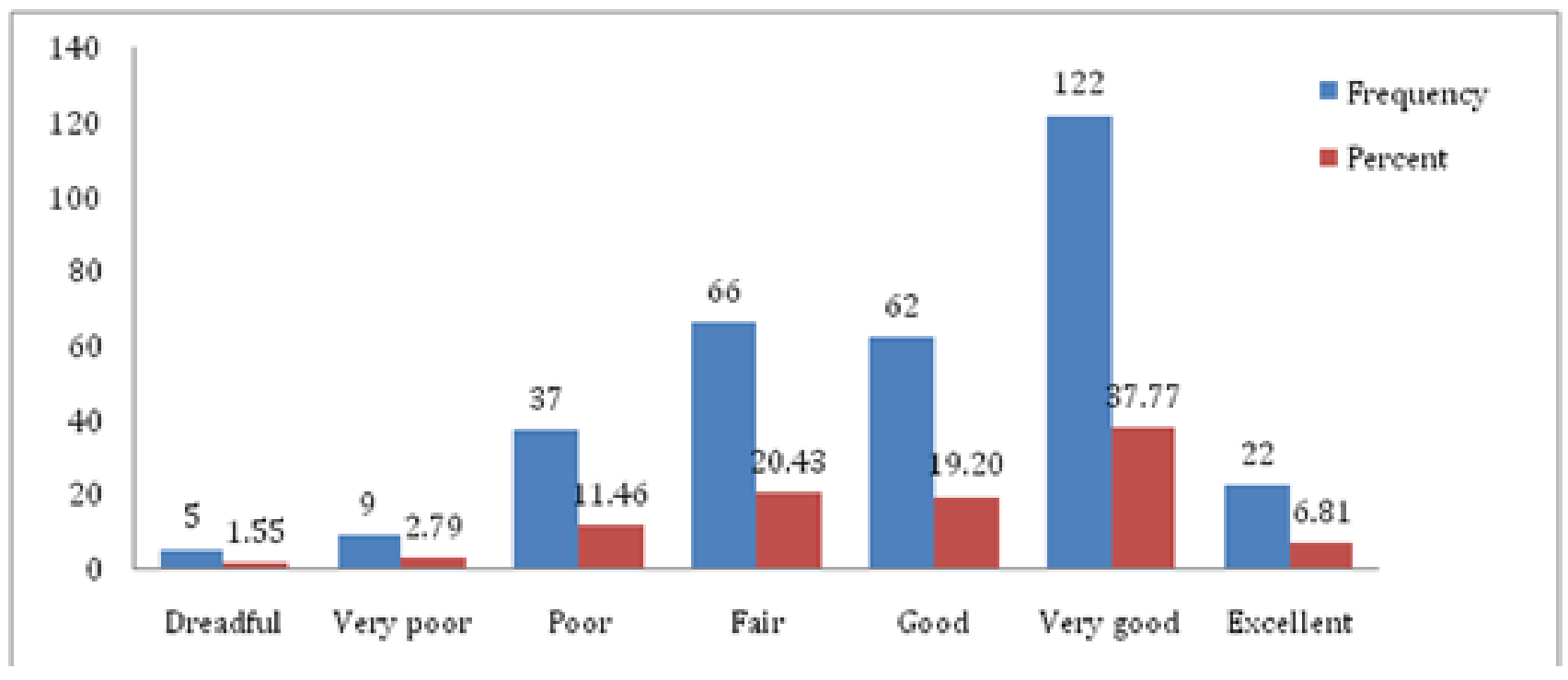

Figure I Distribution of patient perception about inpatient nursing care service among study participants who had been admitted to Arba Minch general hospital, southern Ethiopia, May 2017. 
Table 3 Distribution of patient satisfaction at each wards among study participants who had been admitted to Arba Minch general hospital, southern Ethiopia, May 2017

\begin{tabular}{|c|c|c|c|c|c|c|c|}
\hline \multirow{2}{*}{\multicolumn{2}{|c|}{ Cross tabulation of patient satisfaction score }} & \multicolumn{6}{|c|}{ Type of ward } \\
\hline & & \multirow{2}{*}{\multicolumn{2}{|c|}{$\frac{\text { Medical }(n=185)}{\text { Frequency Percent }}$}} & \multicolumn{2}{|c|}{ Surgical $(n=58)$} & \multicolumn{2}{|c|}{ Obstetric/Gyn $(n=80)$} \\
\hline & & & & \multirow{2}{*}{$\begin{array}{l}\text { Frequency } \\
7\end{array}$} & \multirow{2}{*}{$\begin{array}{l}\text { Percent } \\
12.1\end{array}$} & \multirow{2}{*}{$\begin{array}{l}\text { Frequency } \\
7\end{array}$} & \multirow{2}{*}{$\begin{array}{l}\text { percent } \\
8.7\end{array}$} \\
\hline The & Not satisfied & 69 & 37.3 & & & & \\
\hline The amount of time nurses spent with you & Satisfied & 116 & 62.7 & 51 & 87.9 & 73 & 91.3 \\
\hline \multirow{2}{*}{ How capable nurses were at their job } & Not satisfied & 57 & 30.8 & 9 & 15.5 & 7 & 8.7 \\
\hline & Satisfied & 128 & 69.2 & 49 & 84.5 & 73 & 91.3 \\
\hline \multirow{2}{*}{$\begin{array}{l}\text { There always being a nurse around if you } \\
\text { needed one }\end{array}$} & Not satisfied & 78 & 42.2 & 5 & 8.6 & 6 & 7.5 \\
\hline & Satisfied & 107 & 47.8 & 53 & 91.4 & 74 & 92.5 \\
\hline \multirow{2}{*}{ The amount nurses knew about your care } & Not satisfied & 76 & 41.2 & 6 & 10.3 & 3 & 3.8 \\
\hline & Satisfied & 109 & 58.9 & 53 & 89.7 & 77 & 96.2 \\
\hline \multirow{2}{*}{$\begin{array}{l}\text { How quickly nurses came when you called } \\
\text { for Them }\end{array}$} & Not satisfied & 62 & 33.5 & 14 & 24.1 & II & 13.8 \\
\hline & Satisfied & 123 & 66.5 & 44 & 75.9 & 69 & 86.2 \\
\hline \multirow{2}{*}{ The way the nurses made you feel at home } & Not satisfied & 80 & 43.2 & 27 & 46.6 & 17 & 21.3 \\
\hline & Satisfied & 105 & 56.8 & 31 & 53.4 & 63 & 78.7 \\
\hline \multirow{2}{*}{$\begin{array}{l}\text { The amount of information nurses gave to } \\
\text { you about your condition and treatment }\end{array}$} & Not satisfied & 100 & 54.1 & 42 & 72.4 & 44 & 55.0 \\
\hline & Satisfied & 85 & 45.9 & 16 & 27.6 & 36 & 45.0 \\
\hline \multirow{2}{*}{$\begin{array}{l}\text { How often nurses checked to see if you } \\
\text { were Okay }\end{array}$} & Not satisfied & 80 & 43.2 & 22 & 37.9 & 23 & 28.7 \\
\hline & Satisfied & 105 & 56.8 & 36 & 62.9 & 57 & 71.3 \\
\hline \multirow{2}{*}{ Nurses' helpfulness } & Not satisfied & 82 & 44.3 & 10 & 17.2 & 9 & 11.3 \\
\hline & Satisfied & 103 & 55.7 & 48 & 82.8 & 71 & 88.7 \\
\hline \multirow{2}{*}{ The way nurses explained things to you } & Not satisfied & 68 & 36.7 & 13 & 22.4 & 20 & 25.0 \\
\hline & Satisfied & 116 & 63.3 & 45 & 77.6 & 60 & 75.0 \\
\hline \multirow{2}{*}{$\begin{array}{l}\text { How nurses helped put your relatives' or } \\
\text { friends' minds at rest }\end{array}$} & Not satisfied & 89 & 48.1 & 39 & 67.2 & 18 & 22.5 \\
\hline & Satisfied & 96 & 51.9 & 19 & 32.8 & 62 & 77.5 \\
\hline \multirow{2}{*}{ Nurses' manner in going about their work } & Not satisfied & 77 & 41.6 & 10 & 17.2 & 11 & 13.8 \\
\hline & Satisfied & 108 & 58.4 & 48 & 82.8 & 69 & 86.2 \\
\hline \multirow{2}{*}{$\begin{array}{l}\text { The type of information nurses gave to } \\
\text { you about your condition and treatment }\end{array}$} & Not satisfied & 119 & 64.3 & 22 & 37.9 & 31 & 38.8 \\
\hline & Satisfied & 66 & 35.7 & 36 & 62.9 & 49 & 61.2 \\
\hline \multirow{2}{*}{ Nurses' treatment of you as an individual } & Not satisfied & 81 & 43.8 & 7 & 12.1 & 13 & 16.3 \\
\hline & Satisfied & 104 & 56.2 & 51 & 87.9 & 67 & 83.7 \\
\hline \multirow{2}{*}{$\begin{array}{l}\text { How nurses listened to your worries and } \\
\text { Concerns }\end{array}$} & Not satisfied & 73 & 39.4 & 16 & 27.6 & 27 & 33.8 \\
\hline & Satisfied & 112 & 60.4 & 42 & 72.4 & 53 & 66.2 \\
\hline \multirow{2}{*}{$\begin{array}{l}\text { The amount of freedom you were given on } \\
\text { the Ward }\end{array}$} & ${ }_{n}$ Not satisfied & 51 & 27.6 & 5 & 8.6 & 26 & 32.5 \\
\hline & Satisfied & 134 & 72.4 & 53 & 91.4 & 54 & 67.5 \\
\hline How willing nurses were to respond to & Not satisfied & 68 & 36.7 & 12 & 20.6 & 24 & 30.0 \\
\hline your Requests & Satisfied & 211 & 63.3 & 59 & 79.4 & 60 & 70.0 \\
\hline The amount of privacy nurses gave you & Not satisfied & 87 & 47.0 & 44 & 75.9 & 64 & 80.0 \\
\hline & Satisfied & 98 & 53.0 & 14 & 24.1 & 16 & 20.0 \\
\hline Nurses' awareness of your needs & Not satisfied & 120 & 64.8 & 34 & 58.6 & 37 & 46.3 \\
\hline & Satisfied & 65 & 35.2 & 24 & 43.4 & 43 & 53.7 \\
\hline Oye & Satisfied & 65 & 35.1 & 24 & $4 I .4$ & 43 & 53.7 \\
\hline Uverail ratient satistaction sce & Not satisfied & 120 & 64.9 & 34 & 58.6 & 37 & 46.3 \\
\hline
\end{tabular}


Table 4 Multivariable logistic regression of factors predicting the likelihood of patient satisfaction on inpatient nursing care at Arba Minch General Hospital, Southern Ethiopia, May 2017, (n=323).

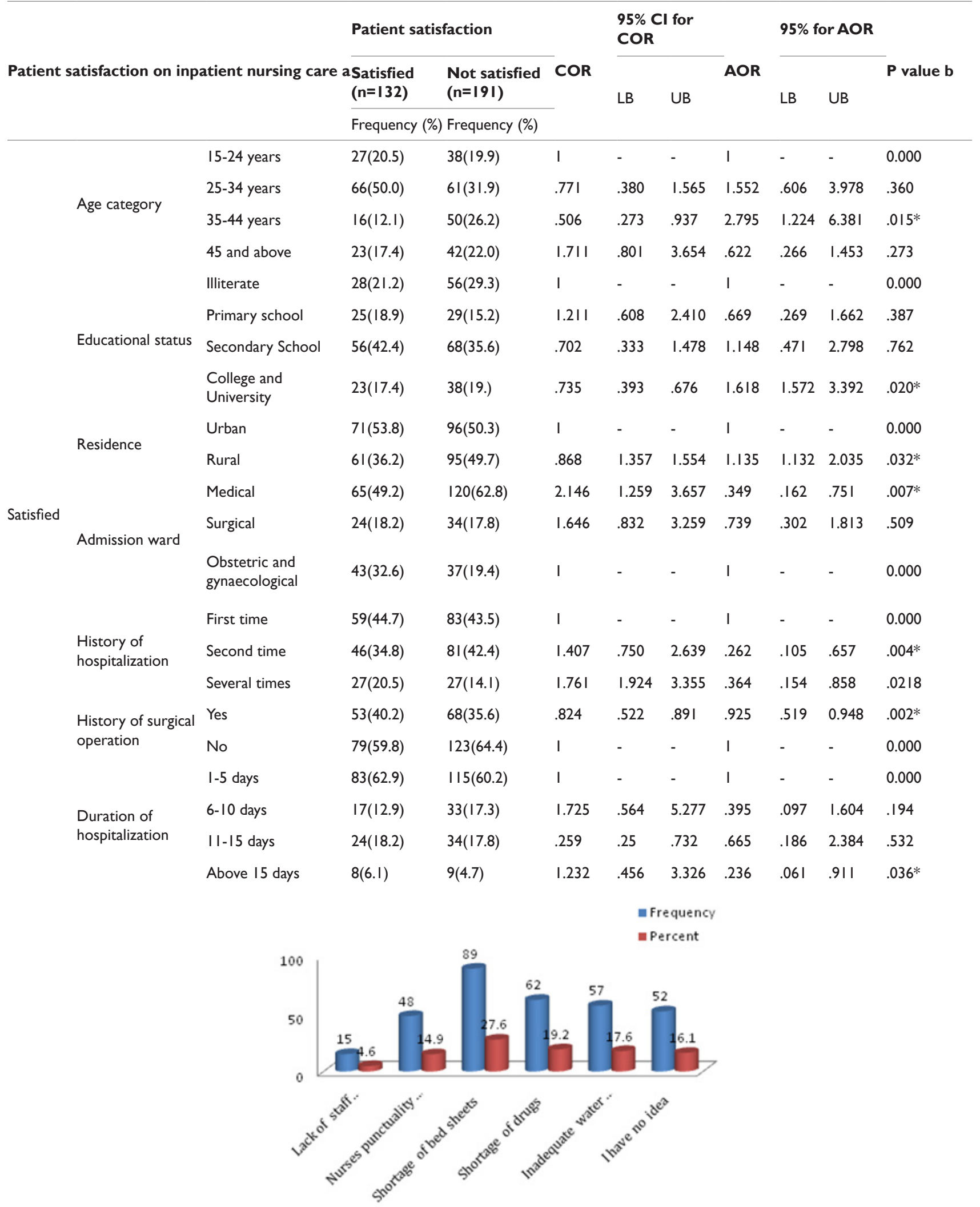

Figure 2 Frequency distribution of reported problems affecting inpatient nursing care among study participants who had been admitted to Arba Minch general hospital, southern Ethiopia, May 2017. 


\section{Discussion}

This study revealed the level of overall adult Patient satisfaction and associated factors in Arba Minch General Hospital. The level of overall patient satisfaction about inpatient nursing service in the hospital was 132(40.9\%). This is lower than study in Tikur Anbassa indicated overall Patient satisfaction $90 \%$ with nursing care in contrary to other studies in the country.$^{27}$ This could be explained variation in socio-demographic characteristic of study participants, tool used to assess patient satisfaction and operational definition given by researchers to satisfaction.

This study revealed that Majority 100(54.1\%), 42(72.4\%), $44(55.0 \%)$ were not satisfied with the amount of information, 119 ( $64.3 \%), 22(37.9 \%)$, and $31(38.8 \%)$ of respondents were not satisfied with the type of information nurses gave to them about their condition and treatment, $120(64.8 \%), 34(38.6 \%)$ and $37(46.3 \%)$ were not satisfied with Nurses' awareness about their needs and $87(47.0 \%)$, $44(75.9 \%)$ and $64(80.0 \%)$ were not satisfied with Patient privacy given by nurses in medical, surgical and Obstetrics and gynecology wards respectively. Different studies conducted in Pakistan and Bangladesh showed that, care givers' politeness, consultation and respect for privacy, explaining them prescription drugs and lab investigations are areas required attention and short waiting time were the most powerful predictor for client satisfaction. ${ }^{18,22}$ This could be explained by lack of staff motivation which could contribute to delivery poor information with respect to quality and amount of information.

Age category 35-44years were 2.7times $[\mathrm{AOR}=2.795(1.224$, $6.381]$ more likely to be satisfied with nursing care service provided when compared with 15-24years. This is different from other Studies which revealed that older respondents generally record higher satisfaction. ${ }^{20}$ This is similar with Study conducted on Adult Patients' Satisfaction with Inpatient Nursing Care in northeast Ethiopia showed that Female patients were more likely to be satisfied with the nursing care as compared to male patients. Patients within the age group of 18-30years were more likely to be satisfied with the nursing care as compared to patients above the age of 61years. ${ }^{25}$

Respondents attended college and University were 1.6 times $[\mathrm{AOR}=1.618(1.572,3.392]$ more likely to be satisfied with nursing care service provided than illiterate once. This similar study with the study in Jimma specialized hospital indicated that patient satisfaction with the health care was found to have a significant association with the age of the respondents $(\mathrm{p}=0.034)$ and educational level of the respondents $(\mathrm{p}=0.003){ }^{12}$

Patients admitted to Medical ward 65(35.1\%) were $[\mathrm{AOR}=0.349$ $(0.162,0.751]$ less likely to be satisfied with inpatient nursing care service than those admitted to obstetrics and gynaecology ward 43(53.7\%). This is against Patient satisfaction study done in Ethiopia which showed which that Patients admitted to Gynecological ward, the amount of time nurses spend with the patient and the type of information nurses given to patients about their condition and their treatment, were factors negatively affecting satisfaction levels. ${ }^{27}$ Improved patient satisfaction in obstetrics and gynaecology ward in this study could be explained increased government commitment given to reduce maternal and child mortality through strengthening capacity of health professionals by giving on job trainings. It could also be explained by difference in study population characteristics and tools used by researchers.
Patients admitted several times and patients admitted second time were $[\mathrm{AOR}=0.364(0.154,0.858)]$ and $[\mathrm{AOR}=0.262(0.105,0.657)]$ less likely to be satisfied with inpatient nursing care provided when compared with those admitted for the first time. This could be explained by patient perception about their illness; patients who perceive their current health is in good condition were more likely to be satisfied as compared to those who perceive their current health status is in poor condition. ${ }^{25}$

Patients who were admitted for more than 15 days were $[\mathrm{AOR}=$ $0.236(0.061,0.911]$ less likely to be satisfied with inpatient nursing care service than those admitted for 1-5 days. This similar with study in Tikur Anbassa indicated those who stayed 11-21 nights had lesser satisfaction than those who stayed less than 10days. ${ }^{26}$ Other study also revealed similar findings length of stay and previous admission were factors associated with patient satisfaction. ${ }^{20}$ However it is different from cross sectional study conducted in Turkey to assess patient satisfaction with nursing care showed that patients who were hospitalized for longer periods were most satisfied. ${ }^{6}$ The variation could be explained by difference in socio-demographic characteristics, tool use and operation definition given for patient satisfaction.

\section{Strengths and limitation of the study}

\section{Strengths}

i. The study utilized a valid and standardized instrument for assessing patient satisfaction

ii. Since interview was made with admitted patients, patients who stay for a long period of time were not missed.

\section{Limitation}

i. Because of time constraints, the interview was held with admitted patients, since exit interview is preferred, to reduce information biases.

ii. Patients may be afraid to say whatever they feel when they were still in the ward. So, the findings of this study might be inflated when we compared to the real findings.

iii. Nurses might also increase their care during process care measurement; this might be inflating the findings of the study.

iv. Being a cross sectional study it showed factors associated adult patient satisfaction and did not explain determinants.

\section{Conclusion and recommendations}

\section{Conclusion}

In conclusion the level of overall adult Patient satisfaction about inpatient nursing service in the hospital was very low. The amount and type of information provided for patients was poor, nurses awareness about patient needs and keeping privacy of patients in all wars also low. Satisfaction of patients admitted to medical ward was relatively lower than patients admitted to surgical and obstetrics and gynaecology ward. Age category 35-44years, Respondents attended college and University, Rural residents, Patients admitted to Medical ward, Patients admitted several times and patients admitted second time, Patients with history of surgical operation and Patients who were admitted for more than 15 days were factors affecting patient satisfaction to inpatient nursing care service. 


\section{Recommendations}

Depending on findings of this we recommend the following responsible bodies

\section{Arba Minch General hospital administration:}

a. Patient satisfaction is one of quality indicators for health care quality; this requires the due attention by hospital administration and staffs to improve satisfaction especially focusing on understanding patient needs, quality and amount of information provided to the patient and protecting patient privacy through providing on job training and support for nurses.

b. Improving drug supply, water supply and availability of bed sheets that could improve nurses motivation to care for their patients

c. The hospital should introduce Operational standards of Nursing Care Practice to new staffs

II. Nursing staff of the Hospital

a. Providing quality care is responsibility of every professionals and giving attention to fill this gap

III. Researchers

a. Those who are interested to conduct study in adult patient satisfaction, it important consider strong study designs to pick out bottle necks of patient satisfaction

\section{Acknowledgements}

We would like to extend our deepest gratitude and appreciation to our advisor Mr. Sisay for his valuable and constructive comments during development of this research paper. We are thankful to Arba Minch General Hospital for provision of useful baseline information. Lastly our special thanks go to study participants, without their participation it is impossible to do this work.

\section{Conflict of interests}

There is no financial or personal relationship(s) which may have inappropriately influenced us in writing this article.

\section{References}

1. Tahir Ahmed, Assefa N, Demisie A, et al. Levels of Adult Patients' Satisfaction with Nursing Care in Selected Public Hospitals in Ethiopia. Int J Health Sci. 2014;8(4):371-379.

2. Locker D, Dunt D. Theoretical and methodological issues in sociological studies of consumer satisfaction with medical care. Soc Sci Med. 1978;12(4A):283-292.

3. Andaleeb SS. Service quality perceptions and patient satisfaction: a study of hospitals in a developing country. Soc Sci Med. 2001;52(9):13591370.

4. Comley AL, De Meyer D. Assessing patient satisfaction with pain management through a continuous quality improvement effort. Journal of pain and symptom management. 2001;21(1):27-40.

5. Shikiar R, Halpern M, Mc Gann M, et al. The relation of patient satisfaction with treatment of otitis externa to clinical outcomes. Clin Ther 1999;21(6):1091-1104.

6. Stimson G, Webb B. Ongoing to see the Doctor. London: Routledge and Kegan Paul; 1975.
7. Bekele Chaka. Adult Patient Satisfaction with Nursing Care adissabeba. Ethiopia; 2005

8. Donabedian A. Introduction to Quality Assurance in Health Care. USA: Oxford University; 2003.

9. Rita Munley Gallagher. Senior Policy Fellow, National Center for Nursing Quality, Revised: American Nurses Association; 2010.

10. The Health Boards Executive. Measurement of Patient Satisfaction, Health Strategy Implementation Project; 2003.

11. Tateke, Mirkuzie Woldie, Shimeles Ololo. Determinants of patient satisfaction with outpatient health services at public and private hospitals in Addis Ababa, Ethiopia. Afr J Prm Health Care Fam Med. 2012;4(1):384.

12. Fekadu A, Mosse A, Hailemichael Y. Assessment of clients' satisfaction with health service deliveries at Jimma University Specialized Hospital. Ethiop J Health Sci. 2011;21(2):101-109.

13. Tourangeau AE. Impact of hospital nursing care on 30-day mortality for acute medical patients. Cancer. 2005;104(5):975-984.

14. Hart S, Bergquist S, Gajewski B, et al. Reliability testing of the national database of nursing quality indicators pressure ulcer indicator. $J$ Nurs Care Qual. 2006;21(3):256-265.

15. Weisman JS, Rothschild JM, Bendavid E, et al. Hospital workload and adverse events. Med Care. 2007;45(5):448-454.

16. Wagner D, Bear M. Patient satisfaction with nursing care: a Concept analysis within a nursing framework. J adv Nurs. 2009;65(3):692-701.

17. Fahad AF. The effect of nursing care on overall patient satisfaction and its predictive value on return-to-provider behaviour. A survey study. Qual Manag Health Care. 2005;14(2):116-120.

18. Saadia A, Imran A, Farzin T, et al. Patient satisfaction level in surgical ward of tertiary care hospital in Karachi, Pakistan. Pakistan Oral and Dental J. 2014;34(2)

19. Dzomeku VM, Atinga Ba, Etilayoo, et al. In-patient satisfaction with nursing care:A case study at Kwamen krumah hospital. International Journal of Research in MHS. 2013;2(1):1-6.

20. Birhanu Z, , Assefa T, Woldie M, et al. Determinants of satisfaction with health care provider interactions at health centers in central Ethiopia. BMC Health Serv Res. 2010;10:78.

21. Quintana JM1, González N, Bilbao A, et al. Predictors of patient satisfaction with hospital health care. BMC Health Ser Res. 2006;6:102.

22. Mendoza Aldana J, Piechulek H, al-Sabir A. Client satisfaction and quality of health care in rural Bangladesh. Bull World Health Organ. 2001;79(6):512-517.

23. Sumeet S, Paramjeet Kaur, Paramjeet Kaur. Patient satisfaction levels in a tertiary care medical college in Punja, North India. Int J Dev Health 2013;1(4):1-11.

24. Mohsen A, Asadi-Lari M, Tamburini M, Gray D (2004) Patients' needs, satisfaction, and health related quality of life: Towards a comprehensive model. Health and Qual Life Outcomes 2:32.

25. Kokeb Haile E. Adult Patients' Satisfaction with Inpatient Nursing Care and Associated Factors in an Ethiopian Referral Hospital, Northeast, Ethiopia. Advances in Nursing. 2016;7.

26. Birna A. The quality of hospital services in eastern Ethiopia: Patient's perspective. Ethiop J Health Dev. 2006;20(3):1-2.

27. Mulugeta M, Aster Berhe, Ashenafi Shumye, et al. Assessment of adult patients' satisfaction and associated factors with nursing care at Tikur Anbassa hospital. Int J Nurs Midwifery. 2014;6(4):1-9. 